\title{
ANTOINE BERMAN NA CHINA: A TRADUÇÃO E O IDEOGRAMA OU O ALBERGUE DAS LETRAS LONGÍNQUAS
}

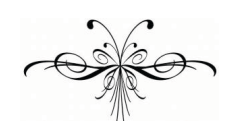

RAQUEL ABI-SÂMARA

$\mathrm{O}$ título remete claramente ao livro de Antoine Berman (19421991), La traduction et la lettre ou l'auberge du lointain, publicado pela primeira vez na França em 1985, e traduzido para o português, em 2007, com o título A tradução e a letra ou o albergue do longínquo. As reflexões de Berman nesse livro concentram-se, estritamente, na tradução literária, ou, se preferirmos, na tradução de obras literárias. Em defesa de uma tradução que privilegie a "letra", de uma tradução do "texto enquanto letra", Berman desenvolve seu entendimento do que vem a ser uma tradução ética: aquela que considera a "textualidade”, a "corporalidade”, a "carnalidade", por assim dizer, do Estrangeiro, sendo, por isso, capaz de abrigar, de acolher, de albergar no texto traduzido o que vem de um mundo por vezes tão distante e longínquo. Daí a escolha de Berman pela expressão "l'auberge du lointain", tirada de uma canção de amor do trovador occitano Jaufré Rudel, do século XII, em que canta o amor longínquo, remoto. Pergunta-se: qual a relação do "albergue do longínquo" e dos conceitos bermanianos tais como "tradução ética", "tradução-da-letra”, entre outros, com os ideogramas chineses e, por fim, com a China? Cabe aqui começar com a explicação da paródia no título deste ensaio.

Em disciplina lecionada recentemente no mestrado em Estudos da Tradução na Universidade de Macau, China, escolhi o livro de Antoine Berman como suporte para as discussões sobre "Tradução e Literatura Comparada". O objetivo do curso, entre outros, era o de oferecer a oportunidade aos estudantes de perceber e analisar aproximações e divergências, identidades e descontinuidades na transmissão estética de textos das tradições literárias da China e do Ocidente. Em vez de se concentrar em detalhes técnicos, o curso visava a orientar os mestrandos para abrangentes questões culturais e ideológicas, envolvidas na percepção da tradução e da literatura comparada. Os oito alunos que frequentaram o curso procediam, em sua maioria, da China continental, e todos, sem exceção, licenciaram-se em Língua e Cultura Portuguesa, em diversas universidades chinesas, sendo que quatro deles se licenciaram na Universidade de Macau (UM). Vale destacar a singularidade da 
pós-graduação (mestrado e doutorado) na UM, por ser a única na Ásia a oferecer especialização em tradução direcionada ao par lingúistico chinêsportuguês. Afinal, a presença e a influência dos portugueses em Macau, como se sabe, começou em tempos remotos, ou seja, no início do século XVI.

Como a maioria dos mestrandos não dominava francês, e como não há ainda versões dos livros de Antoine Berman para o chinês, a leitura foi feita em língua portuguesa, na tradução criteriosa de Mauri Furlan, Marie-Hélène Catherine Torres e Andréia Guerini. Dois meses antes de iniciar o semestre, enviei A tradução e a letra ou o albergue do longínquo para os estudantes inscritos na disciplina e solicitei que fizessem uma resenha curta da obra. Queria ter uma ideia da qualidade da leitura que por eles seria feita e dos níveis de dificuldades que poderiam surgir ante uma obra reflexiva que considero de elevada sofisticação intelectual. Nenhuma resenha, no entanto, foi-me apresentada, e o motivo era de que a leitura lhes parecera bastante hermética, conforme relataram, com períodos muito longos e complicados, além de uma grande quantidade de conceitos desconhecidos ou pouco familiares para o grupo. Percebi, de saída, que o desafio era maior do que imaginara inicialmente. Apesar da pouca receptividade inicial dos estudantes à obra, insisti em sua leitura ao longo do semestre, intercalada de textos teóricos auxiliares, textos literários curtos (poemas e mini-contos que seriam traduzidos do português para o chinês), e também análises de traduções de poemas do par chinês-português, feitas por tradutores eminentes, como Yao Jingming, António Graça de Abreu, Gil de Carvalho, Haroldo de Campos.

Durante e ao final do semestre, pôde-se avaliar o resultado positivo do investimento em A tradução e a letra. Os horizontes de leitura oferecidos pelo livro não se limitaram a questões específicas de tradução literária. Abrangeram também a filosofia e a literatura ocidentais, num sentido amplo e panorâmico, desde os pré-socráticos a Heidegger, desde Antígona ${ }^{1}$ a Franz Kafka e Rainer Maria Rilke. Logo nas primeiras aulas, ao perceber uma lacuna de conhecimento dos estudantes com relação à filosofia ocidental, dediquei dois encontros, no total de seis horas, para a apresentação de conceitos filosóficos fundamentais, aliados à produção da grande literatura ocidental, numa vasta linha do tempo, que ia do século VIII a.C. ao século XX. A partir de então, tornaram-se menos distantes os conceitos apresentados por Berman, tais como platonismo ou tradução platônica, a tradução como experiência (à luz de Heidegger), estrangeirização (na intuição de Schopenhauer), as reflexões de Goethe e dos primeiros românticos alemães - como Kleist, Hölderlin, Schlegel, à luz das críticas kantianas.

Nas universidades chinesas, a licenciatura em Língua Portuguesa, pelo que pude perceber por esses alunos de mestrado, não oferecem cursos específicos sobre a história geral da filosofia, das artes e da literatura ocidentais. Seria muito proveitoso se cursos dessa natureza fossem incluídos na grade curricular da graduação em Português, ao menos ao longo de um semestre, de preferência no último ano da graduação, quando há o domínio maior do idioma pelos alunos. Desse modo, os estudantes poderiam olhar para a língua, a literatura e a cultura portuguesas dentro de um contexto mais amplo, pensá-las e

\footnotetext{
${ }^{1}$ A tradução de Friedrich Hölderlin (1804) da tragédia de Sófocles (442 a.C.) é analisada na obra de Berman como exemplo de tradução bem sucedida e inovadora, por privilegiar basicamente a "letra" do texto grego.
} 
contextualizá-las a partir daquilo que se produziu de mais significativo e inovador no pensamento e na cultura do Ocidente, desde Homero e dos présocráticos. Uma vez recebidas essas noções na graduação, ao ingressarem nos cursos de mestrado, os estudantes teriam, sem dúvida alguma, um rendimento muito maior em questões reflexivas como as propostas por Antoine Berman.

Os livros de Berman, como se disse acima, não foram ainda traduzidos para o chinês, e, em artigos recentes de acadêmicos chineses, que li em inglês e em português, não há referências diretas a livros de Berman. Os teóricos da tradução ocidentais citados com mais frequência nesses artigos são Nida, Catfort, Vinay \& Darbelnet, Even-Zohar, Venuti, Toury e Munday. E entre os conceitos sobre tradução mais usados nas dissertações de mestrado da UM, pelo que pude observar, estão os conceitos de equivalência, equivalência dinâmica (Nida), e estrangeirização e domesticação (atribuídos a Venuti, e por vezes a Schleiermacher, que foi quem primeiro apresentou tal noção). Uma abordagem, digamos, filosófica da tradução de literatura, como a de Berman, não é, portanto, familiar à tradição contemporânea de reflexões sobre a tradução na China. A tradução e a letra é uma obra pautada não no binômio teoria e prática, mas sim no par reflexão e experiência, sendo essa última entendida no sentido heideggeriano. Ao defender a "tradução como experiência", Berman cita Heidegger:

Fazer uma experiência com o que quer que seja (...) quer dizer: deixá-lo vir sobre nós, que nos atinja, que caia sobre nós, nos derrube e nos torne outro. Nesta expressão, “fazer” não significa em absoluto que somos os operadores da experiência: fazer quer dizer, aqui, passar, sofrer do início ao fim, aguentar, acolher o que nos atinge ao nos submetermos a ele...” (Berman, 2007, p.18)

A tradução de literatura, portanto, consiste em tarefa muito mais abrangente do que somente a "passagem” interlingual de um texto. A literatura é algo da ordem da experiência do homem no mundo; por isso, traduzi-la não consistirá em ação muito diversa. Não se deve restringir o entendimento da tradução literária a uma mera tarefa de comunicação de mensagens de um idioma a outro. As tramas e tessituras de uma obra, o modo como as letras vão também tecendo e construindo os sentidos, impedem que se entenda a literatura de modo platônico, como simples sentidos veiculados por letras. Ao apresentar a ideia da tradução como experiência, Berman cita a poetisa Marina Tsvetaeva, tradutora de Rilke:

Hoje desejo que Rilke fale através de mim. Na linguagem corrente, isto se chama traduzir. (...) Mas a tradução significa também outra coisa. Não se passa somente de uma língua a outra língua (o russo, por exemplo), passa-se também de um lado ao outro do rio. Faço passar Rilke em língua russa, assim como ele me fará passar um dia a outro universo. (Berman, 2007, p.23)

A tradução da literatura, como revelam as palavras de Marina Tsvetaeva, é algo nitidamente mais intenso e profundo do que uma simples aplicação de técnicas na passagem de um texto de uma língua a outra. Se ela permite "passar um dia a outro universo", conforme a metáfora de Tsvetaeva, 
não deixa de ser uma experiência, no sentido filosófico do termo. ${ }^{2}$ Ela seduz 0 tradutor a um posicionamento reflexivo, em busca de fidelidade e exatidão em sua tarefa de "passar de um lado ao outro do rio". Para Berman,

fidelidade e exatidão se referem a uma certa postura do homem em relação a si mesmo, aos outros, ao mundo e à existência. E, do mesmo modo, certamente, em relação aos textos. Na sua área, o tradutor é tomado pelo espírito de fidelidade e de exatidão. É a sua paixão, e é uma paixão ética e não literária ou estética. (...) O ato ético consiste em reconhecer e em receber o Outro enquanto Outro. (...) Acolher o Outro, o Estrangeiro, em vez de rejeitálo ou de tentar dominá-lo, não é um imperativo. Nada nos obriga a fazê-lo. (Berman, 2007, p. 68)

O caminho sugerido por Berman para se chegar a uma tradução ética seria o de se traduzir o mais próximo possível da "letra" do texto. Mas, a tradução da "letra", ou a tradução "literal", não é um conceito simples em Berman. Não se trata, em hipótese alguma, de uma tradução palavra-porpalavra, trata-se de uma tradução vinculada à letra de modo muito mais complexo, num sentido mais amplo do que aquele que comparece nas enciclopédias de tradução, o que é ilustrado pelo autor com análises de três importantes traduções que considera "literais": a Antígona de Sófocles, traduzida por Hölderlin, o Paraíso Perdido de Milton, por Chateaubriand, e a Eneida de Virgílio, na versão de Klossowski. Não caberia aqui desenvolver em detalhes o raciocínio de Berman sobre a tradução literal, mas, somente para que se tenha uma ideia do seu nível de complexidade, apresenta-se uma de suas conclusões sobre a Antígona de Hölderlin:

esta tradução 'literal' irá num duplo sentido: reencontrar as significações primeiras das palavras gregas, mas, para transmiti-las até nós, chegar ao sentido original das palavras alemãs, usar a 'velha língua' de Lutero, o dialeto suábio etc., para tentar restabelecer a força falante do grego pela força falante do alemão (idem, p.81).

Citemos, ainda, mais uma reflexão de Berman sobre a tradução “literal”, ao comentar a versão de Klossowski da Eneida:

Uma das características da tradução de Klossowski, veremos, é que ela se realiza a partir de um vasto horizonte poético, indo de Mallarmé a Bonnefoy, passando por Claudel, Sain-John Perse, os surrealistas e Jouve. Atenção: não estou dizendo que Klossowski usou esses poetas para traduzir. Mas sua tradução é impensável sem as possibilidades poéticas que eles abriram (idem, 114).

No contexto atual, em que "a equivalência dinâmica [de Nida] continua sendo o evangelho da maioria dos tradutores” (idem, p.17), traduções dessa natureza, ou seja, traduções "literalizantes", continuam sendo entendidas como “experimentais”. Nas palavras de Berman, “a tradução 'literalizante’ constitui a

\footnotetext{
2 Como assinala Berman, “de Kant a Hegel e Heidegger, a experiência é um conceito fundamental da filosofia. O mesmo vale para a reflexão”. (Berman, 2007, p.19)
} 
face escondida, o continente negro da história da tradução ocidental”33 (idem, p.17).

Falar de tradução "literal”, tanto na França quanto na China, não deixa de ser uma questão bastante polêmica. Pensemos no discurso sobre a tradução na China do século XX, que ao menos até os anos 80 esteve centrado na controvérsia da "tradução literal versus tradução livre” (Chang, 2009, p. 309). A tradução literal, se pensada no esquema convencional de tradução palavra-porpalavra, e não no sentido mais amplo proposto por Berman, poderia representar tarefa impossível quando da passagem de um texto escrito num idioma sinotibetano, como o chinês, para um idioma indo-europeu, por exemplo. Como o chinês é uma língua não flexionada, ou seja, visto que "as palavras não sofrem modificações de acordo com o número, o gênero, o caso, o tempo, a voz ou o modo (...), e não há conjugação nem declinação” (Chu, 2000, p. 207), seria inviável traduzir literalmente do chinês para o português, ou para qualquer outro idioma ocidental, em função de normas gramaticais bastante diversas entre as línguas. A usual omissão do sujeito na poesia clássica chinesa, por exemplo, como destaca Yao Jingming, significa enorme dificuldade ao ser traduzida para o português, pois nem sempre parece possível manter a indeterminação do sujeito nos versos em língua portuguesa. "Na poesia chinesa”, escreve Yao,

\begin{abstract}
a omissão do sujeito é quase total. Mesmo num contexto que implica o aparecimento claro do sujeito e o complemento indireto, o sujeito também pode ser omitido. (...) A tendência do poeta chinês no sentido de evitar o aparecimento do sujeito pessoal mostra uma escolha consciente, que permite situar o sujeito numa relação interior com os seres e as coisas (Yao, 2001, p.22-3).
\end{abstract}

Sob a perspectiva da literalidade bermaniana, a tradução de um poema chinês, embora o autor não tenha tratado do tema, possivelmente iria manter a indeterminação do sujeito, uma vez que ela representa a interiorização dos elementos exteriores, traço eminente do espírito taoísta e, em última instância, da tradicional cultura chinesa.

A partir dos anos 80, os Estudos da Tradução na China começam a receber maior influência das teorias e estudos tradutológicos produzidos no Ocidente. Em contrapartida, há uma tendência de sistematização dos pensamentos e teorias da tradução de origem chinesa, o que se constata nas várias antologias que vêm sendo publicadas nas últimas décadas, entre elas: An Anthology of Essays on Translation, organizada por Luo Xinzhang, e publicada em 1984, não tanto tempo depois do final da Revolução Cultural (1966-1976); Twentieth-Century Chinese Translation Theory: Models, Issues and Debates (2004), de Leo Tak-hung Chan; e An Anthology of Chinese Discourse on Translation -Volume I: From Earliest Times to the Buddhist Project (2006),

\footnotetext{
${ }^{3}$ Vale destacar que Berman desenvolve suas reflexões sobre a desvalorização da tradução literalizante no Ocidente com base, sobretudo, na tradição de tradução na França, onde quase sempre se privilegiou um estilo etnocêntrico e hipertextual de tradução, em que não há lugares para estrangeirismos, para a acolhida do Outro.
} 
organizada por Martha Cheung. Na introdução de sua antologia, Luo Xinzhang ${ }^{4}$ apresenta uma genealogia das teorias da tradução na China, e resume que

o sistema de teorização chinês, grosso modo, gira em torno dos conceitos de anben (tradução de acordo com a fonte), qiuxin (fidelidade), shensi (semelhança espiritual) e huajing (esfera da transformação). Esses conceitos, entre si relacionados, foram elaborados principalmente por quatro tradutores/acadêmicos ilustres - Dao An, Yan Fu, Fu Lei (1908-1966) e Qian Zhongshu (1910-1998) - em diferentes períodos da história chinesa. (apud Bai Liping, p. 427)

A obra de Luo, no entanto, não é a primeira antologia de ensaios sobre tradução que aparece na China. Em 1981 foi publicada uma antologia de mesmo título (em pinyin, Fanyi lunji) em Hong Kong, por Liu Ching-chih. Há ainda outra coleção de ensaios publicada no mesmo ano da antologia de Luo (1984), cujo título, em pinyin, é Fanyi yanjiu lunwenji (Antologia de Ensaios sobre Estudos da Tradução), editada pela Associação de Tradutores da China ${ }^{5}$. Como observa Bai Liping,

essas últimas coleções de ensaios dão a impressão de que as teorias da tradução chinesas começaram a aparecer no final do século XIX, particularmente com o artigo de Yan Fu (1854-1921) intitulado 'tianyan lun yi liyan' (Introdução à Tradução de Evolution and Ethics de Thomas Huxley, publicada em 1898). Esse artigo focaliza as dificuldades para atingir o ' $x i n$ ' (fidelidade), o ‘ $d a$ ' (expressividade) e o 'ya'(elegância), e é considerado, de modo geral, o trabalho referencial sobre teoria da tradução na China. Liu afirma explicitamente em seu prefácio que as teorias da tradução na China, estrito senso, começam com Yan Fu. (...) A antologia de Luo, por sua vez, começa com os ensaios sobre a tradução dos sutras budistas, escritos pelos principais monges budistas, como Dao An (312/314-385), Xuan Zang (600664) e Fa Yun (1088-1158), ao longo de diversas dinastias, desde o século III. (Bai, 2009, p. 424)

No artigo "Repertoire Transfer and Resistance - The Westernization of Translation Studies in China”, Nam Fung Chang afirma que a teoria de Yan Fu dominou o discurso sobre tradução na China até os anos 1980, e que as três dificuldades por ele destacadas, especialmente a "elegância” (ya), foram propostas para justificar suas estratégias extremamente orientadas para o texto alvo. Conforme Chang,

duas décadas mais tarde, no início dos anos 1920, com a cultura toda em crise, começaram a prevalecer as estratégias orientadas para o texto fonte, especialmente nos círculos literários de esquerda (...). Lu Xun, o principal escritor e tradutor revolucionário da época, defendeu a 'fidelidade em lugar da fluidez’ na tradução, como um meio de importar não apenas novas idéias mas também novas formas de expressão, a fim de remediar a 'imprecisão' do chinês. Dado seu status literário e político, além do suporte de Mao Tse-Tung nos anos 1950, o discurso de Lu sobre tradução foi canonizado e continuou a influenciar tradutores por mais de meio século. (Chang, 2009, p. 309)

\footnotetext{
${ }^{4}$ Luo, renomado tradutor de literatura francesa, traduziu Le Rouge et le Noir de Stendhal. Segundo Bai Liping, seus princípios de tradução estão pautados no pensamento tradicional chinês de tradução. (Cf. Bai, 2009, p. 426)

${ }^{5}$ http://www.tac-online.org.cn/.
} 
Nam Fung Chang destaca duas ondas de ocidentalização nos Estudos da Tradução na China, a primeira ocorrendo no início dos anos 80. Depois da Revolução cultural, diz, havia uma espécie de vácuo na cultura chinesa, além de uma insatisfação geral com relação aos repertórios estabelecidos. "A tradução”, afirma Chang, "um importante meio de transferência de repertórios ocidentais, acabou por remodelar a cultura” (idem, p. 310). As teorias ocidentais introduzidas nessa época foram, sobretudo, as dos lingüistas Nida, Catford e Wilss. Como lembra Chang, essas teorias, que inovaram de certo modo o pensamento sobre a tradução na China, já haviam sido, no entanto, suplantadas no Ocidente pela Teoria do Escopo, pela Teoria dos Polissistemas e por outras teorias da tradução fundamentadas não mais em questões lingüísticas, mas sim culturais. Segundo Chang, a teoria de Nida teve uma rápida repercussão na prática e nos Estudos da Tradução na China: “Os princípios de equivalência pareciam prometer um fim à antiqüíssima controvérsia de 'tradução literal versus tradução livre', e a metodologia dessa teoria era atrativa por ser considerada científica e acadêmica” (idem, p. 311). Bai Liping acrescenta que a teoria da tradução de Nida foi introduzida na China por Tan Zaixi, e que teve uma receptividade tão grande a ponto de tornar popular o seguinte dizer: 'yan bi cheng naida' - falar de teorias da tradução é o mesmo que falar de Nida (Bai, 2009, p. 426).

A segunda onda de ocidentalização, segundo Chang, foi iniciada por jovens acadêmicos em Hong Kong, na década de 1990, que abandonaram teorias prescritivas e adotaram modelos descritivos, tais como a Teoria dos Polissistemas, os Estudos Descritivos da Tradução e a Teoria do Escopo, e, posteriormente, também outras teorias culturais, como as do Pós-Colonialismo e a do Feminismo - em poucos anos, a maioria dos pesquisadores da tradução de Hong Kong adotou essa chamada "virada cultural” (Chang, 2009, p. 311). Mais de dois terços dos artigos publicados em 2005 no Chinese Translators Journal ${ }^{6}$, principal revista da China especializada em tradução, referem-se a teorias ou a tradutores estrangeiros ${ }^{7}$. Cabe verificar se já foi incluída alguma referência a Antoine Berman nessas revistas. Em uma busca de 20 minutos nos websites, em chinês, sobre publicações de textos referentes a Berman e a estudos tradutológicos, verificou-se que não há traduções de livros de Berman para o chinês. No entanto, encontrou-se uma série de artigos acadêmicos que abordam estudos do autor, mas nada especificamente sobre $A$ tradução e a letra ou o albergue do longínquo $^{8}$. Fica a pergunta: por que as duas ondas de ocidentalização dos estudos tradutórios na China não englobaram a recepção de Antoine Berman? Que contribuições os pensamentos de Berman poderiam trazer para os Estudos da Tradução na China?

Se pensarmos em termos de tradução de poesia, o conceito de "literalidade" em Berman, embora um pouco difuso e por vezes contraditório"

\footnotetext{
${ }^{6}$ http://www.tac-online.org.cn/en/tran/2009-10/09/content_3175320.htm.

${ }^{7}$ A observação é de Zhang Jinghao, citada por Nam Fung Chang (Chang, 2009, p.312).

8 A busca na internet foi feita por um colega chinês do Departamento de Português da Universidade de Macau, em 18/06/2012.

${ }^{9}$ Em “Algumas reflexões sobre a tradução à letra segundo Berman”, Comellas questiona o conceito de literalidade em Berman: “as traduções mostradas por Berman atingem o objetivo de estrangeirizar os textos, de evitar a invisibilidade da tradução (...). Não fica claro, no entanto,
} 
poderia ter excelente rendimento, uma vez que se opõe àquela tradução dita platônica, que não deixa de ser a tradução dominante na poesia do par chinêsportuguês (ou do par chinês e quaisquer outros idiomas ocidentais). Pelo fato de o chinês ser uma língua tonal, diferentemente das línguas ocidentais, parte-se tacitamente do princípio da impossibilidade de transcriação dos tons ${ }^{10}$ e da questão da sonoridade em geral. Nesse caso, o que ocorre é que a tradução de poesia privilegia estritamente o sentido, em detrimento da letra, ou, se preferirmos, em detrimento do ideograma, e daí a ser entendida como tradução platônica, etnocêntrica e hipertextual, como define Berman. Ou seja, o sentido é transportado de um sistema ideográfico a um sistema fonológico de escrita, ou vice-versa, sem a consideração da materialidade gráfica ou sonora das letras e/ou dos caracteres chineses ${ }^{31}$. Desse modo, perde-se aquele encantamento dos ideogramas chineses desvelado ao Ocidente por Ernest Fenollosa em seu ensaio "Os caracteres da escrita chinesa como instrumento para a poesia", quando escreve que a língua chinesa, por sua etimologia constantemente visível, "conserva a seiva primitiva, não é como um galho seco que serve de bengala” (Fenollosa, 2000, p.129). Fenollosa, no entanto, não focaliza a parte sonora da escrita ideográfica, suas diversas possibilidades de frases melódicas, dadas as diferenças entre os diversos dialetos chineses ${ }^{12}$. A metáfora dos galhos secos remete a uma comparação dos caracteres da escrita chinesa com as letras que utilizamos como símbolos fonéticos, que acabam por gerar, nas palavras do autor, uma "anemia do discurso moderno":

que consigam isso através de uma tradução à letra. De fato, com frequência as traduções exemplares que Berman mostra fogem radicalmente dela. (...) Mas então é muito difícil distinguir, na análise microtextual de uma tradução, o que é traduzir perto da letra e o que é domesticar, se não é que consideramos como critério a estranheza: o ‘estranho’ é literalidade que não decalca, enquanto o 'normal' é domesticação. Assim sendo, afinal o que importa não é a letra, mas a criação de estranheza, a vontade da tradução de lembrar-nos que o Outro é Outro, estrangeiro" (Comellas, 2011, p.7).

${ }^{10}$ Ao discorrer sobre as características do discurso chinês em "Interação entre linguagem e pensamento em chinês", Yu-Kuang Chu aborda a questão dos tons: "Como existem cerca de 420 sílabas em mandarim, em contraposição às 1200 do inglês, e como um dicionário chinês completo contém aproximadamente 50.000 palavras, há muitas palavras pronunciadas com o mesmo som ou sílaba. Como recurso para diferenciar algumas delas, usam-se os tons” (Chu, 2000, p. 204-5). Em seguida, Chu refere-se à comparação de Herrlee Greel dos quatro tons às quatro maneiras de pronunciar os yes em inglês, com bases no livro The Seven English Speech Tones, Analysed and Identified with Musical Tones and Chinese Speech Tones, de Jee Sane Woo (1959).

${ }^{11}$ Mesmo Haroldo de Campos, em suas belíssimas transcriações de poemas chineses para 0 português, talvez raramente tenha levado em consideração os aspectos melódicos, musicais, sonoros dessa poesia. Em contrapartida, produziu, de modo genial e criativo, repetições e rimas, digamos, gráficas, espaciais, o que se pode “ver” claramente no poema de Wang Wei, traduzido por Haroldo com o título "O refúgio dos cervos". Sempre que possível, o tradutor explora a repetição de elementos gráficos dos ideogramas, numa tradução nitidamente semiótica, em que repetições de elementos gráficos são transcriadas em repetições ou ecos de elementos sonoros. (Cf. a tradução de Haroldo em: CAMPOS, 2010, p. 51)

${ }^{12}$ A experiência de analisar traduções de poemas do par chinês-português com os alunos de mestrado em Estudos da Tradução da UM foi enriquecedora, uma vez que os poemas podiam ser ouvidos em duas distintas leituras feitas pelos alunos: em mandarim (ou, em pinyin, putonghua, dialeto oficial na China) e em cantonês (em Macau, na região de Cantão, predomina o dialeto cantonês, e a escrita resiste em se manter com ideogramas tradicionais, ao passo que os ideogramas simplificados já são utilizados no restante da China). 
Numa palavra fonética, há muito pouco, ou mesmo nada, que exiba os estágios embrionários de seu desenvolvimento. Ela não ostenta a metáfora em sua própria aparência. Esquecemos que a personalidade outrora significou, não a alma, e sim a máscara da alma. É esta espécie de coisas que não pode ser esquecida quando se utilizam os símbolos chineses (idem).

Para os chineses, no entanto, essa etimologia visual dos caracteres chineses divisada por Fenollosa passa numa leitura trivial sem que seja necessariamente notada ${ }^{13}$. Os ideogramas, no caso, acabam por se assemelharem aos galhos secos dos símbolos fonéticos, a bengalas de sentido, sem valor intrínseco, sem seiva primitiva, com a função apenas de intermediadores de sentidos. Se pensarmos numa tradução de poesia do chinês para o português, por exemplo, as intuições e perspectivas de Berman sobre a tradução "literal" poderiam talvez servir de indicadores de caminho para o resgate daquilo que respira no poema como unidade intrínseca de sentidos, musicalidades e imagens (metafóricas e gráficas).

Como se viu, prevaleceram na China, durante longo tempo, reflexões sobre a tradução literal, mas obviamente essa "literalidade" em muito difere da perspectiva apresentada por Berman, uma vez que consistem em modelos estritamente lingüísticos. Como exemplo desses modelos, Zhang Meifang e Pan $\mathrm{Li}$, no artigo "Introducing a Chinese Perspective on Translation Shifts", comparam os métodos de tradução definidos por Vinay \& Darbelnet - tradução direta e tradução oblíqua - com dois métodos gerais de tradução do teórico chinês Loh Dian-yang, que são a tradução literal e a tradução livre (Zhang \& Li, 2009, p. 365). Os procedimentos, métodos e taxonomia dos teóricos canadenses datam de 1958, mesmo ano em que Loh publicou os dois volumes de sua obra em chinês (“Tradução: seus princípios e técnicas”). Em termos práticos, uma aproximação dos métodos de tradução apresentados por Loh (dicção, amplificação, omissão, repetição, negação etc) com as tendências deformadoras da tradução, desenvolvidas por Berman (racionalização, clarificação, alongamento, enobrecimento, destruição dos ritmos etc) no segundo capítulo de A tradução e a letra, poderia ser um caminho interessante para a análise da tradução de obras literárias do chinês para o português ou o inglês, e vice-versa.

E, voltando ao ponto de partida deste ensaio, isto é, à leitura de Antoine Berman na disciplina de mestrado da UM: aquela leitura que parecera inóspita e hermética à primeira vista, inclusive por não se apresentar inicialmente como uma teoria com nível plausível de aplicabilidade, foi-se desdobrando ao longo do semestre num convite à reflexão e num interesse maior pela literatura e pela filosofia, o que se verificou nas avaliações finais do curso, pois afinal (e uso aqui as palavras de Berman para concluir):

\footnotetext{
${ }^{13} \mathrm{O}$ texto de Fenollosa foi por mim escolhido como texto de apoio da disciplina "Tradução e literatura comparada”, no mestrado em Estudos da Tradução da UM, e foi apresentado em aula por um dos mestrandos chineses. Foi bastante curioso acompanhar a percepção do texto pelos estudantes. As imagens desdobradas nos caracteres por Fenollosa, ao contrário de óbvias, como era o esperado, pareciam para eles uma visão singular de um poeta, uma poetização de símbolos desprovidos de imagens.
} 
a tradução pode perfeitamente passar sem teoria, não sem pensamento. E esse pensamento sempre se efetua num horizonte filosófico. (...) A tradução, com seu objetivo de fidelidade, pertence originariamente à dimensão ética. Ela é, na sua essência, animada pelo desejo de abrir o Estrangeiro enquanto Estrangeiro ao seu próprio espaço de língua. Isto não significa, em absoluto, que historicamente tenha sido sempre assim. Pelo contrário, o objetivo apropriador e anexionista que caracteriza o Ocidente sufocou quase sempre a vocação ética da tradução. A 'lógica do mesmo’ quase sempre prevaleceu. Isso não impede que o ato de traduzir obedeça a uma outra lógica, a da ética. Por isto, retomando a bela expressão de um trovador, falamos que a tradução é, na sua essência, o ‘albergue do longínquo’ (Berman, p.19; p. 71)

\author{
Raquel Abi-Sâmara \\ raquelmag@umac.mo \\ Prof. doutora, Universidade de Macau
}




\section{Referências bibliográficas}

BAI, Liping. "Anthology Compilation as a Purpose-driven Activity. Luo Xinzhang's Account of Translation Theories in 'Our Country'. In: The Translator. Volume 15, Number 2 (2009), 423-429

Berman, Antoine. A tradução e a letra ou o albergue do longínquo. Tradução de Mauri Furlan, Marie-Hélène Catherine Torres e Andréia Guerini. Rio de Janeiro: 7Letras/PGET, 2007.

CAmpos, Haroldo. Escrito sobre jade - Poesia clássica chinesa reimaginada por Haroldo de Campos. São Paulo: Ateliê Editorial, 2009.

ChAn, Leo Tak-hung (org.). Twentieth-Century Chinese Translation Theory: Models, Issues and Debates. Amsterdam \& Philadelphia: John Benjamins, 2004.

ChAnG, Nam Fung. "Repertoire Transfer and Resistance. The Westernization of Translation Studies in China”. In: The Translator. Volume 15, Number 2 (2009), 305-325.

Cheung, Martha (org.). An Anthology of Chinese Discourse on Translation. Volume I: From Earliest Times to the Buddhist Project. Manchester: St. Jerome, 2006.

CHU, Yu Kuang. "Interação entre linguagem e pensamento em chinês”. In: CAMPOS, Haroldo de. Ideograma. Lógica, poesia, linguagem. São Paulo: Edusp, 2000. p. 203-227

Comellas, Pere. "Algumas reflexões sobre a tradução à letra segundo Berman”. In: Scientia Traductionis. n. 9, 2011.

FENOLlOSA, Ernest. "Os caracteres da escrita chinesa como instrumento para a poesia”. In: CAMPOS, Haroldo de. Ideograma. Lógica, poesia, linguagem. São Paulo: Edusp, 2000. p.109-148

Luo, Xinzhang. An Anthology of Essays on Translation. Beijing: Commercial Press, 1984.

YAO, Jingming. A poesia clássica chinesa: uma leitura de traduções portuguesas. Macau: Coleção Estudos de Macau, Centro de Publicações Universidade de Macau, 2001.

Zhang, Meifang \& LI, Pan. "Introducing a Chinese Perspective on Translation Shifts”. In: The Translator. Volume 15, Number 2 (2009), 351-374 